\title{
The Word, Phrase, and Sentence Productivity, and Average Length of Utterances among Children with Mild Mental Retardation
}

\author{
Astuty $^{1}$, Mursiana Ekawati ${ }^{2}$, Molas Warsi Nugraheni ${ }^{3}$ \\ \{astuty@untidar.ac.id ${ }^{1}$, astuty64@gmail.com ${ }^{2}$ \} \\ 1,2,3 Universitas Tidar, Magelang, Indonesia
}

\begin{abstract}
This study aims to describe and explain the patterns of words, phrases, sentences, and the average length of utterances in the CMMR speech based on the minimum and maximum ability. This research approach is a qualitative one that is observationally controlled through a cross-sectional design. The research data were in the form of written stories, conversations, and records of field data. The source of the data was the MMRC of Year 5. The technique of collecting data was recording and observation. The findings of this study were as follows: (1) based on the maximum capacity, the productivity of the word productivity was that the noun increased by $86 \%$, the verbs by $81 \%$, function words by $75 \%$, adjectives by $76 \%$, pronouns by $78 \%$, numerals by $83 \%$, and adverbs by $75 \%$. (2) Based on the maximum capacity, the productivity of phrases was that the prepositional phrases increased by $72 \%$, nominal phrases by $88 \%$, verbal phrases by $70 \%$, numeral phrases by $76 \%$, pronominal phrases by $50 \%$, conjunctive phrases by $100 \%$, and adverbial phrases by $100 \%$. (3) Based on the number of clauses related to the minimal capabilities, the sentence productivity found in the form of simple sentences and can be found in neither compound nor complex sentences and based on the maximum capabilities productivity of simple sentence increased by $86 \%$ and it was found that there was neither compound nor complex sentences. Based on the completeness of the sentence elements, it was found that according to the minimal ability there were $15 \%$ of complete sentences and $85 \%$ of incomplete sentences and based on the maximum capabilities, there was a $25 \%$ increase of complete sentences and a decrease by $75 \%$ of incomplete sentences. (4) Based on the minimum capability, the average length of utterances (ALU) was5,69 and based on the maximum capacity; it increased by 6,24 .
\end{abstract}

Keywords: Productivity, word, phrase, sentence, average length of utterances

\section{INTRODUCTION}

Language is one of the parameters in the development of children's speech and language competence involves cognitive, sensory-motoric, psychological, emotional, and environmental development around the child. Language skills generally fall on receptive and productive abilities (listening and understanding) and expressive capability (speaking and writing). The speaking ability is more assessable than the other capabilities so that the discussion on language 
skills is more often associated with the speaking ability. Proficiency in speaking and using language is influenced by intrinsic factors (of the child) and extrinsic factors (of the environment). Intrinsic factors are inborn conditions, including the physiology of the organs involved in speaking and using language. Meanwhile, the extrinsic factors are stimuli that surround children, especially words which are heard or addressed to the children, also determine the development of children's language skills.

The children's language skills are acquired sophisticatedly through several means. Children can learn any language they hear in their daily lives fast. Almost all children are generally able to master the basic rules of language at the age of 3-4 years. Any language has an unlimited number of sentences that they had never heard. This means that when learning a language, children are not merely imitating the utterances they heard, but also learn abstract grammatical concepts in connecting words into construct sentences. Through interaction with members of the family, peers, teachers, and caregivers, children learn communicative competence or haw to use language appropriately and strategically in social situations [1]

Chaer [2] states that two processes occur when a child is acquiring a language, the process of competency as well as the process performance. The competence process is a requirement for the performance process. The competence includes phonological components, the syntactic components, and semantic components that do not stand discretely but simultaneously take place by the development of the children's age. So, based on the children's development of the age, their language skills develop through the stages, each involves the three components. The performance process consists of two stages, namely the process of understanding and the process of implementing or producing words, phrases, clauses, and sentences. The process of understanding involves the ability to perceive sentences they hear, whereas the process producing involves the ability to generate or produce words, phrases, clauses, and sentences. Both of these processes later form children's linguistic competence.

An article entitled "Early Predictors of Language in Children With and Without Down Syndrome" written by Paul J. Yoder (Vanderbilt University) and Steven F. Warren (University of Kansas) in American Journal of Mental Retardation Volume 109, Number 4: 285-300, July 2004 [3] reported that MMRC has limited intellectual abilities, resulting in their experiencing various obstacles in the social, emotional, and personality development in performing activities of their daily life. MMRC has an IQ between 50-70, a low intelligence level, but they are still able to be educated explicitly with special programs and methods to develop. MMRC is a child who still has the potential to master academic subjects in elementary school; they are also able to perform social adaptation so that in the long run they can rely on themselves in the community and are able to work to support some oa all of their adult lives.

The Ministry of Educations [4] explains that an MMRC is a child who has an alow level of the intellectual quotient (IQ); the IQ level is less than 70. As a result, they have problems in producing words, phrases, clauses, and sentences. Moreover, because of their mental retardation, MMRC also faces obstacles in adjustment to the environment, delays in intelligence, social adaptation, and academic subjects. However, in addition to the above shortcomings, there is still potential for MMRC to be further educated. The objectives of MMRC education, among other things, are for the children to be able to care for themselves, adjust themselves to home life, process social skills, work so that in time they can earn a living for themselves in accordance with the skills they process.

Based on the preliminary data it was found that MMRC experiences obstacles in producing words and sentences, i.e. the spoken words are unclear, the words they produced tend to be single words containing a pattern of two-syllable words, and sentences they produce are not in accordance with the rules of sentence construction or chaotic. In terms of the smoothness in 
producing speech, MMRC found several difficulties. Despite the many obstacles in speaking, MMRC is still possible to be guided in order to achieve maximum capacity. It was proved that after teachers provided intervention in the form of probing questions, they could continue the story that had to stop several times.

In relation to the development of the MMRC's maximum capacity in speaking, Vygotsky's argued that there is an area that is very sensitive to be actualized in children's minds. This area is called the Zone of Proximal Development (ZPD). ZPD is the distance between a person's actual ability level (henceforth minimum capability) and potential ability level (henceforth maximum capability) [5]. Based on the ZPD theory, interventions to actualize the MMRC's maximum capability can be done by providing probing questions. Such questions are asked when MMRC has difficulties in telling stories or time of intervention by probing question is called a Probing Question Technique.

On the basis of the description above, it can be concluded that research on the productivity of words, phrases, sentences, and the average speech length (ASL) in the MMRC speech is very important. Research on the productivity of words, phrases, sentences, and ASL in MMRC's speech does not simply describe and explain the MMRC's speech based on the research problem, but also intends to find a wide range of minimum capabilities and maximum ability to use the Vygotsky's theory about the Zone of Proximal Development (ZPD) and the probing question technique. Based on the background of the problem, formulation of the problem of this research is "How is the productivity of words, phrases, sentences, and the average length of utterance in the MMRC's speech based on the minimum and maximum ability?

\section{METHOD}

This study used a qualitative approach conducted in controlled observation. It was crosssectionally designed, meaning that it was performed at only one point of time. The study was a naturalistic study because it aimed to understand the phenomenon experienced by the source of research data in a holistic manner by describing words in natural contexts [6]. In the context of this study, a natural phenomenon was an MMRC's speech while attending teaching and learning processes and while taking a rest outside the classroom. In this study, the researcher positioned herself as a key instrument because she acted as a human instrument that served to fix the focus of the study, the research data sources, the data collection, the reduction, the presentation, and conclusions/ verifications of the findings.

The research background was SLB Negeri Ungaran and SLB Negeri Semarang. There were two types of data in this study i.e., chunks of staries, chunks of conversations, and field records data. The data were drawn when the MMRC attended the teaching and learning process of Indonesian Subject based on the Competency Standards (SK) and the BasicCompetence (KD) issued by the National Education Standards Agency (BSNP) for children with special needs type $\mathrm{C}$ or the 5th-grade second-semester MMRC. The SK for the second semester is "giving an opinion on factual issues" with KD "telling opinion on factual issues" and "responding to factual issues". The research data were also taken as the MMRC was sorting the classroom.

The data source of this research was the 5th-grade MMRC at SLB Negeri Ungaran, consisting of 6 pupils, 3 males and 3 females. Meanwhile, in SLB Negeri Semarang, seven pupils consisted of 3 males and 4 females. With the $13 \mathrm{MMRC}$, the data collected were deemed sufficient to be analyzed in order to answer the research problem.

Data for this research were collected in two ways, namely recording technique and observation technique. In order to obtain valid data, it was necessary to triangulate them. The data were then analyzed in three stages, namely (1) data reduction, (2) data presentation, and 
(3) inference or verification of the research findings. Although in the three phases, there were different activities, the process was intertwined with each other, so that the realization was integrated.

\section{RESULT AND DISCUSSION}

In this study, the measure of productivity is determined on the basis of the "physical productivity", i.e., quantitative production, including (1) the productivity of words based on word class, (2) productivity phrases based on classes of word, (3) the productivity of the sentence based on the number of clauses and completeness of the elements, and (4) the average length of utterances produced the MMRC. The research findings are grouped according to the minimum and maximum capabilities.

\section{a. Word Productivity}

Analysis of the word productivity in this study was based on the words classes. Based on the book entitled "Tata Bahasa Baku Bahasa Indonesia" [7] word classes consist of verbs, adjectives, adverbs, nouns, pronouns, numerals, and function words.

Based on the minimum and maximum capability, the word productivity was found in the order of nouns, verbs, function words, adjectives, pronouns, numerals, and adverbs. Based on the maximum capability, the words produced by the MMRC quantitatively increased, i.e. the number of nouns increased by $86 \%$, while the number of verbs increased by $81 \%$, the number of function words increased by $75 \%$, the number of adjectives increased by $76 \%$, pronouns increased to $78 \%$, numerals increased by $83 \%$, and adverbs increased by $75 \%$. The detailed findings of word productivity are presented in Table 1 below.

Tabel 1. The Word Productivity Based on Minimum and Maximum Capability

\begin{tabular}{lccc}
\hline Word Productivity & Minimum Capability & Maximum Capability & $\begin{array}{c}\text { Percentage of } \\
\text { Increase }\end{array}$ \\
\hline Noun & 83 & 575 & 86 \\
\hline Verb & 49 & 255 & 81 \\
\hline Function word & 23 & 89 & 75 \\
\hline Adjective & 19 & 79 & 76 \\
\hline Pronoun & 17 & 76 & 78 \\
\hline Numeral & 7 & 39 & 75 \\
\hline Adverb & 5 & 20 & 79 \\
\hline Total & 203 & 1133 & \\
\hline
\end{tabular}

Table 1. Shows that the number of nouns produced by the MMRC was very dominant. In connection with this, Dardjowidjoyo [8] states that in the acquisition of vocabulary, actual words around the pupils were mastered the earliest. Dardjowidjoyo [8] argues that until the age of two years, Echa has mastered 471 words with nouns on the highest rank. In terms of the productivity order, the number of words produced MMRC is not much. Different from that 
produced by normal children. However, based on the quantity, a number of words produced by normal children because before intervention, the number of words produced by MMRC consists of only a few short sentences. After intervention or based on their maximum capability, the MMRC's word productivity increased by $79 \%$.

\section{b. Phrase Productivity}

Phrase productivity in this study was analyzed based on the word classes. Based on the word classes, phrases consist of verbal phrases, adjectival phrases, nominal phrases, pronominal phrases, numerical phrases, prepositional phrases, and conjunctional phrases [9].

Based on the minimum capability, the phrases were found to be in the sequence of the prepositional phrase, nominal phrase, verbal phrase, the numeral phrase, and pronominal phrase. Meanwhile, conjunctional phrases and adverbial phrases were not found. Quantitatively, the prepositional phrase is the category of phrase, which is the most commonly found. Based on the maximum capability, all kinds of phrases were found in the MMRC's utterances in the order of prepositional phrases, nominal phrases, verbal phrases, numeral phrases, pronominal phrases, conjunctional phrases, and adverbial phrases. Based on the maximum capability, the phrase productivity increased, i.e., prepositional phrases increased by $72 \%$, nominal phrases increased by $88 \%$, verbal phrases increased by $70 \%$, numeral phrases increased by $76 \%$, pronominal phrases increased by $50 \%$, conjunctional phrases increased by $100 \%$, and adverbial phrases increased by $100 \%$. The detailed findings related to phrase productivity are presented in Table 2 below.

Tabel 2. Phrase Productivity Based on Minimum and Maximum Capability

\begin{tabular}{lccc}
\hline Productivity & Minimum Capability & Maximum Capability & $\begin{array}{c}\text { Percentage of } \\
\text { Increase }\end{array}$ \\
\hline Prepositional & 21 & 74 & 72 \\
\hline Nominal & 5 & 49 & 88 \\
\hline Verbal & 4 & 14 & 70 \\
\hline Numeral & 3 & 15 & 76 \\
\hline Pronominal & 3 & 6 & 50 \\
\hline Conjunctional & 0 & 11 & 100 \\
\hline Adverbial & 0 & 3 & 100 \\
\hline Total & 36 & 172 & 79 \\
\hline
\end{tabular}

Tabel 2. Shows that the productivity of the phrase is dominated by a prepositional phrase. The domination of prepositional phrase productivity has an impact on the sentence pattern with the intensity of the presence of the adverbial function of each sentence pattern produced by the MMRC. Prior to intervention, the phrases produced by the MMRC declined. This happens because before receiving the intervention, the MMRC speech did not develop. Their utterances consisted only of a few short and simple sentences. After the intervention, the number of phrases 
productivity increased by $79 \%$ due to the MMRC speech that is more productive. In this case, the MMRC was able to complete their utterances based on the topics they discussed.

\section{c. Sentence Productivity}

In this study, the sentence productivity was analyzed based on the number of clauses and the completeness of their elements. The analysis that is based on the number of clauses in each sentence intends to reveal the MMRC capability in producing simple sentences and compound/complex sentences. Meanwhile, an analysis which was based on the completeness of the sentence elements aimed to reveal complete sentences and incomplete sentences produced by the MMRC. The analysis of the sentence productivity, which was based on the number of clauses and the completeness of the sentence elements were grouped into two categories based on the minimum and maximum capability. By such comparison, it is known that the MMRC capability could the maximized in producing sentences by providing proper guidance or intervention.

According to "Tata Bahasa Baku Bahasa Indonesia" [7], based on the number of clauses, sentences are divided into two, namely a simple sentence and compound/complex sentence. Based on the number of clauses, the sentence productivity within the minimum capability was limited only to simple sentences and no compound/ complex sentence was produced. Based on the maximum capability, simple sentence productivity increased by $86 \%$. Meanwhile, no compound/complex sentence was found.

Based on the completeness of the elements, the sentences are divided into two categories, namely (1) complete sentences and (2) incomplete sentences. A complete sentence is a sentence consisting of at least a free clause. Therefore, the minimum basis of a complete sentence is that it consists of a free clause. In this study, complete sentences include simple sentences and compound/complex sentences. An incomplete sentence is a sentence that has no subject and/ or predicate. It usually occurs in a discourse in that the element that does not appear is already known or previously mentioned.

On the minimum capability, it was found that the number of complete sentences produced by the MMRC was only 15\%. The rest, i.e., $85 \%$ were in the form of incomplete sentences. Based on the maximum capacity, the number of complete sentences produced by the MMRC increased by $10 \%$. Those, based on maximum capacity, the number of complete sentences produced the MMRC increased by $25 \%$. The number of incomplete sentences decreased to $75 \%$. The detailed findings on the sentence productivity based on the minimum and maximum capability are presented in Table 3 below.

Tabel 3. The Sentence Productivity Based on the Minimum and Maximum Capability

\begin{tabular}{lccc}
\hline Sentence Productivity & Minimum Capability & $\begin{array}{l}\text { Maximum } \\
\text { Capability }\end{array}$ & $\begin{array}{c}\text { Percentage of } \\
\text { Increase }\end{array}$ \\
\hline Simple sentence & 8 & $75 n$ & 86 \\
\hline $\begin{array}{l}\text { Compound/complex } \\
\text { sentence }\end{array}$ & outlayer & outlayer & - \\
\hline $\begin{array}{l}\text { Completeness of the } \\
\text { elements }\end{array}$ & $8(15 \%)$ & & 86 \\
\hline
\end{tabular}


Complete sentence

Incomplete sentence

$45(85 \%)$

$223(75 \%)$

$-10$

Based on Table 3. It can be inferred that based on the minimum and maximum capability, the MMRC can only produce simple sentences. Meanwhile, the productivity of compound and complex sentences decreases. The result of this study is in line with Bernstein and Tigermean's study, stating that due to the language disorders experienced by the MMRC, the sentences they produce are in the form of short and simple sentences. Based on the completeness of its elements, the utterances produced by the MMRC are generally incomplete sentences. The condition occurs because the utterances produced by the MMRC are short and mostly dominated by phrases and a row of words with a chaotic structure that do not meet the criteria as complete sentences.

\section{d. The Everage Length of Utterances (ALU)}

In order to measure the average length of utterances (ALU), this study refers to the opinion of Dardjowidjoyo [8] that the ALU is calculated based on the number of morphemes in utterances divided by the number of utterances. Generally, as many as 100 utterancess counts. Of the amount, the number of morphemes is calculated. The result is then divided by 100 . There are several rules to calculate the number of morphemes in the utterances. A component like "kereta api" or a proper name such as "Abdul Majid" counts as one morpheme because it has one meaning. Besides that, an affix also counts as one morpheme.

The ALU counting in this study was based on the utterances produced the number of utterances produced by the $10 \mathrm{MMRC}$ as the sources of research data. Of the ten sources, three were excluded from the ALU calculation because their utterances were categorized as outlayer. The ALU of the MMRC was calculated based on the minimum capability of producing utterances, i.e. 30. The total number of morphemes that resulted from them was 170 . Prior to intervention, the average length of utterances was 170:30 $=5,67$. The MMRC's ALU was calculated based on the maximum capacity of producing the 100 utterances. The total number of morphemes counted from the MMRC's ALU was 684:97 =6,24.

Based on the above findings, it can be concluded that according to the minimum and maximum capability, the ALU of the MMRC is under the average normal children. When compared to the findings on Echa's ALU at the age of 4,3 years, hers was 7,8 [8]. Based on the maximum capacity, the MMRC's ALU was still under Echa's. The low MMRC's ALU was due to the fact that they just produced simple sentences. The above findings imply that the MMRC's lack of syntax was quite serious. Despite the fact, with the intervention of MMRC's ALU could be improved. Based on these findings, it is possible that with early and intensive intervention, the MMRC was more productive in producing compound/complex sentences. This will undoubtedly increase the ALU of the MMRC.

\section{CONCLUSION}

Regarding the findings on the productivity of words, phrases, sentences, and average length of utterances (ALU), it can be concluded that based on the order of appearance according to the minimum and maximum capability the productivity of words among the MMRC is not much 
different from that of normal children, in the order of nouns, verbs, function words, adjectives, pronouns, numerals, and adverbs. Based on the number of words, the number of words they produced was under that of normal children. However, based on the maximum capacity, the productivity of words of the MMRC increased by $79 \%$. Based on the order of appearance, the MMRC's productivity of phrases was like that of normal children, i.e. prepositional phrase, nominal phrase, verbal phrase, numeral phrase, pronominal phrase, conjunctional phrase, and adverbial phrase. The difference is in the number of phrases produced. Although the phrase productivity of the MMRC experienced deficit, based on the maximum capacity, the phrase productivity increased by $79 \%$. Based on the number of clauses, sentence productivity was dominated by a simple sentence. Compound and complex sentences were not found in this study. Based on the completeness of the elements, according to the minimal capability, their utterances consist of complete sentences $15 \%$ and incomplete sentences $85 \%$. Based on the maximum capability, the sentence productivity of the ALU based on the minimum ability of was 5, 67 and the ALU based on the maximum capacity was 6,24.

\section{REFERENCE}

[1] D. Hymes, Foundations in Sociolinguistics: An ethnographic approach. Philadelphia: University of Pennsylvania Press., 1974.

[2] A. Chaer, Linguistik Umum. Jakarta: Rineka Cipta, 2007.

[3] P. J. Yoder and S. F. Warren, "Early predictors of language in children with and without Down syndrome," Am. J. Ment. Retard., vol. 109, no. 4, pp. 285-300, Jul. 2004, doi: 10.1352/0895-8017(2004)109<285:EPOLIC>2.0.CO;2.

[4] Departemen Pendidikan Nasional, Pedoman Guru Pendidikan Merawat Diri untuk Anak Retardasi Mental. Jakarta: CV Karya Sejahtera, 2003.

[5] A. N. Cahyono, "Vygotskian Perspective : Proses Scaffolding untuk Mencapai Zone of Proximal Development ( ZPD ) Peserta Didik dalam Pembelajaran Matematika," Semin. Nas. Mat. dan Pendidik. Mat., no. November, pp. 443-448, 2010.

[6] L. J. Moleong, Metodologi penelitian kualitatif. Bandung: Remaja Rosdakarya, 2010.

[7] A. M. Alwi, Hasan; Dardjowidjojo, Soenjono; Lapoliwa, Hans; Moeliono, TATA BAHASA BAKU BAHASA INDONESIA EDISI KETIGA. Jakarta: Balai Pustaka, 2000.

[8] S. Dardjowidjojo, Echa : kisah pemerolehan bahasa anak Indonesia. Jakarta: Gramedia Widiasarana Indonesia, 2000.

[9] L. Y. Konisi, Sintaksis Bahasa Indonesia. Kendari: JPBS FKIP Unhalu, 2010. 